\title{
Decreased mean platelet volume predicts poor prognosis in invasive bladder cancer
}

\author{
Xin Wang ${ }^{1, *}$, Ming-Ming Cui ${ }^{1, *}$, Yangyang $\mathrm{Xu}^{2,3, *}$, Li Liu ${ }^{3}$, Ye Niu ${ }^{4}$, Tiemin Liu ${ }^{1,5}$, Zhi- \\ Ping Liu, ${ }^{6}$ Rui-Tao Wang ${ }^{1,3}$ and Kai-Jiang $\mathbf{Y u}^{7,3}$ \\ ${ }^{1}$ Department of Internal Medicine, Harbin Medical University Cancer Hospital, Harbin Medical University, Harbin, Heilongjiang \\ 150081, China \\ ${ }^{2}$ Department of Urinary Surgery, Harbin Medical University Cancer Hospital, Harbin Medical University, Harbin, Heilongjiang \\ 150081, China \\ ${ }^{3}$ Heilongjiang Academy of Medical Science, Harbin, Heilongjiang 150081, China \\ ${ }^{4}$ Department of Geriatrics, The Second Affiliated Hospital, Harbin Medical University, Harbin, Heilongjiang 150086, China \\ ${ }^{5}$ Division of Hypothalamic Research, Department of Internal Medicine, UT Southwestern Medical Center, Dallas, TX 75390, USA \\ ${ }^{6}$ Department of Internal Medicine, University of Texas Southwestern Medical Center, Dallas, TX 75390, USA \\ ${ }^{7}$ Department of Intensive Care Unit, Harbin Medical University Cancer Hospital, Harbin Medical University, Harbin, Heilongjiang \\ 150081, China \\ *These authors have contributed equally to this work
}

Correspondence to: Rui-Tao Wang, email: ruitaowang@126.com

Kai-Jiang Yu, email: kaijiang_yu@yeah.net

Keywords: bladder cancer, mean platelet volume, prognosis

Received: February 13, $2017 \quad$ Accepted: June 10, 2017

Published: July 12, 2017

Copyright: Wang et al. This is an open-access article distributed under the terms of the Creative Commons Attribution License 3.0 (CC BY 3.0), which permits unrestricted use, distribution, and reproduction in any medium, provided the original author and source are credited.

\section{ABSTRACT}

Background: Altered mean platelet volume (MPV) is implicated in a wide range of cancers. However, the prognostic role of MPV in muscle-invasive bladder cancer (MIBC) remains largely unknown. The purpose of this study was to elucidate the predictive significance of MPV in MIBC.

Method: The retrospective study included 218 consecutive MIBC patients between January 2009 and December 2009. The relationships between MPV and clinicopathological characteristics were analyzed. Kaplan-Meier method and Cox regression were used to evaluate the prognostic impact of MPV.

Result: Of the 218 patients, low MPV levels were detected in $141(64.7 \%)$ patients. Reduced MPV was associated with $T$ stage and histology grade $(p<0.05)$. In the Kaplan-Meier analysis, decreased MPV was significantly associated with a poorer overall survival ( $p=0.007$ ). In the multivariate Cox model, decreased MPV was an independent prognostic index for overall survival $(H R=2.023,95 \% \mathrm{CI}=1.050-3.897, \mathrm{p}=0.025)$.

Conclusion: MPV is easily available in routine blood test. Our results demonstrated that reduced MPV could be regarded as a potential prognosis indicator for clinical outcome in MIBC.

\section{INTRODUCTION}

Bladder cancer (BC) is one of the most frequently diagnosed malignancies and is a common cause of cancerrelated mortality worldwide. Approximately $25 \%$ of the bladder cancers are found to be muscle invasive (MIBC) with a 5-year survival proportion of 33\% [1]. Therefore, developing appropriate and effective biomarkers to predict clinical outcome is crucial for elucidating the mechanism underlying metastasis and recurrence in MIBC, resulting in discovery of novel therapeutic agents.

Platelets play a pivotal role in cancer progression and metastasis. There is emerging evidence to suggest that platelets mediate tumor cell growth, angiogenesis, 
and dissemination [2]. Increased platelets are correlated with a decrease in overall survival and poorer prognosis in various types of cancer, including pancreatic cancer, gastric cancer, colorectal cancer, endometrial cancer, and ovarian cancer [3-7]. However, platelet count is determined by the balance between the rate of production and consumption of platelets. A normal platelet count could conceal the presence of highly hypercoagulative and pro-inflammatory cancer phenotypes in the presence of efficient compensatory mechanisms [8].

Mean platelet volume (MPV), the most commonly used measure of platelet size, is a surrogate marker of platelet activation [9]. Altered MPV levels were found in gastric cancer, ovarian cancer, lung cancer, colon cancer, and breast cancer [10-14]. In addition, MPV is associated with the prognosis in patients with non-small cell lung cancer and multiple myeloma $[15,16]$. However, its clinical implications in MIBC have not been well defined. Therefore, the purpose of the current study was to evaluate the association of MPV levels with prognosis in MIBC cases.

\section{RESULTS}

Between Jan, 2009 and Dec, 2009, a total of 218 MIBC patients were enrolled in this study. Among the 218 patients, 46 (21.1) were women and 172 (78.9) were men, and the median age was $63.2 \pm 9.0$ years (range 31-82).
A ROC curve for OS prediction was plotted to verify the optimal cut-off value for MPV, which was 9.1 fL (Figure 1). It demonstrated that MPV predicts cancer prognosis with a sensitivity of $77.6 \%$ and a specificity of $40.0 \%$ (AUC $=0.591,95 \% \mathrm{CI}: 0.522-0.657, \mathrm{p}=0.031$ ). Then, patients were divided into 2 groups: patients with $\mathrm{MPV} \leq 9.1 \mathrm{fL}$ and patients with MPV $>9.1 \mathrm{fL}$. There were $141(64.7 \%)$ patients with MPV $\leq 9.1 \mathrm{fL}$ and $77(35.3 \%)$ patients with MPV > 9.1 fL.

The relationships between MPV and clinical characteristics were shown in Tables 1 and 2. Our study revealed that MPV was associated with $\mathrm{T}$ stage and histology grade. However, no significant differences were found between the groups with regard to age, gender, multiplicity, growth pattern, distant metastasis, and lymphovascular invasion.

With a median follow up of 60 months, 58 (26.6\%) patients had death events. Patients with MPV $\leq 9.1 \mathrm{fL}$ had a significantly shorter 5-year OS than patients with MPV $>9.1 \mathrm{fL}$ (68.1\% vs. $83.1 \%, \mathrm{p}=0.007)$. The Kaplan-Meier OS curves of the normal versus reduced MPV showed a significant separation (Figure 2).

In univariate analysis, age (categorical variable), MPV (categorical variable), histology grade, lymphovascular invasion, multiplicity, and growth pattern were significant predictors of OS (Table 3$)$. NLR $(\mathrm{p}=0.060), \operatorname{PLR}(\mathrm{p}=0.070)$ and T stage $(\mathrm{p}=0.059)$ showed weak associations. Other parameters were not

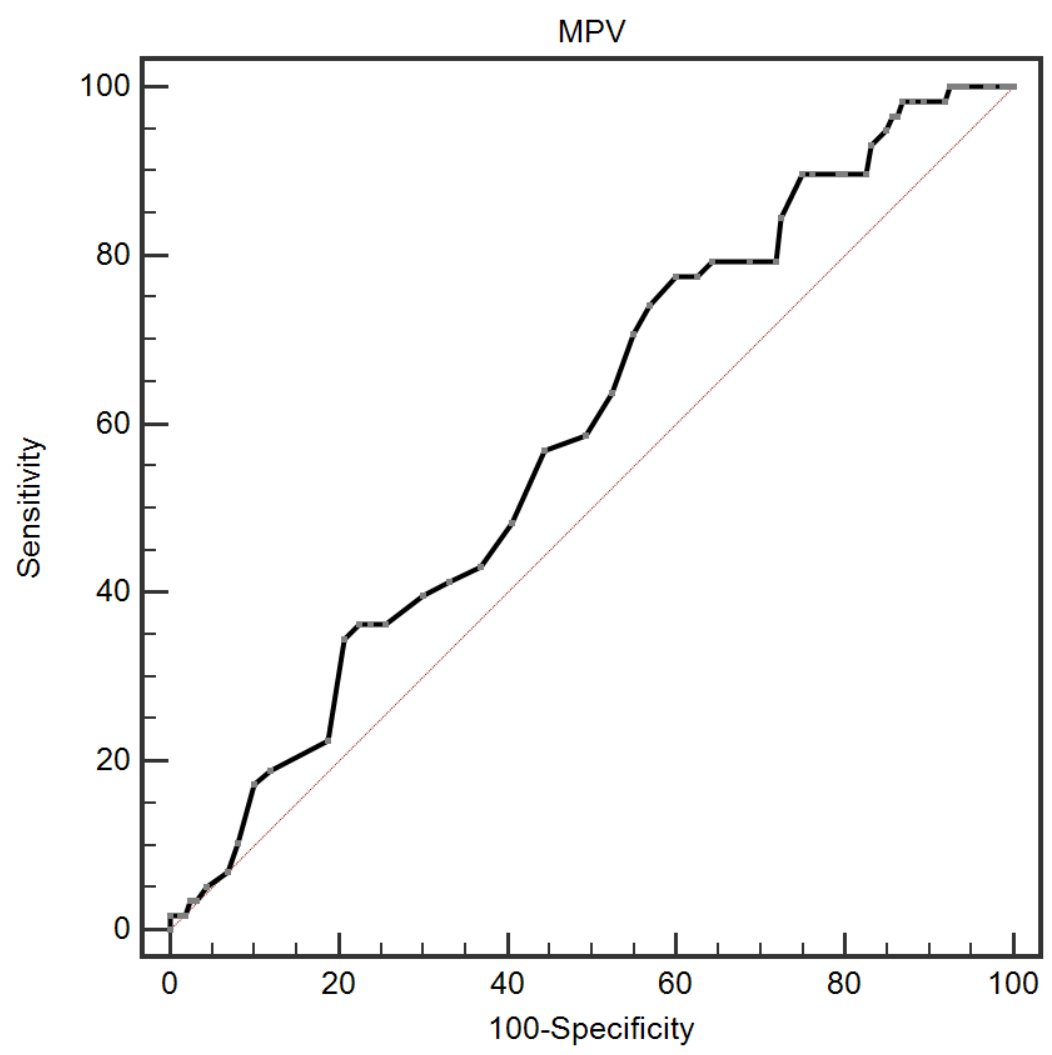

Figure 1: Optimized cut-off value was determined for MPV using standard ROC curve analysis. 
Table 1: Baseline characteristics of the patients according to MPV levels

\begin{tabular}{|c|c|c|c|c|}
\hline \multirow[t]{2}{*}{ Variables } & Total & MPV $>9.1$ & $\mathrm{MPV} \leq 9.1$ & \multirow[t]{2}{*}{ Pvalue } \\
\hline & n (\%) & n (\%) & n (\%) & \\
\hline Age (years) & & & & 0.657 \\
\hline$\leq 65$ & $123(56.4)$ & $45(58.4)$ & $78(55.3)$ & \\
\hline$>65$ & $95(43.6)$ & $32(41.6)$ & $63(44.7)$ & \\
\hline Gender & & & & 0.665 \\
\hline Male & $172(78.9)$ & $62(80.5)$ & $110(78.0)$ & \\
\hline Female & $46(21.1)$ & $15(19.5)$ & $31(22.0)$ & \\
\hline T stage & & & & $<0.001$ \\
\hline $\mathrm{T} 2$ & $144(66.1)$ & $53(9.2)$ & $91(19.2)$ & \\
\hline T3 & $26(11.9)$ & $11(50.4)$ & $15(50.4)$ & \\
\hline $\mathrm{T} 4$ & $48(22.0)$ & $13(40.4)$ & $35(30.4)$ & \\
\hline Histology grade & & & & 0.028 \\
\hline $\mathrm{G} 1+\mathrm{G} 2$ & $114(52.3)$ & $48(62.3)$ & $66(46.8)$ & \\
\hline G3 & $104(47.7)$ & $29(37.7)$ & $75(53.2)$ & \\
\hline Multiplicity & & & & 0.474 \\
\hline Solitary & $126(57.8)$ & $47(61.0)$ & $79(56.0)$ & \\
\hline Multifocal & $92(42.2)$ & $30(39.0)$ & $62(44.0)$ & \\
\hline Growth pattern & & & & 0.699 \\
\hline Papillary & $84(38.5)$ & $31(40.3)$ & $53(37.6)$ & \\
\hline Non-papillary & $134(61.5)$ & $46(59.7)$ & $88(62.4)$ & \\
\hline Lymphovascular invasion & & & & 0.081 \\
\hline Yes & $82(37.6)$ & $23(29.9)$ & $59(41.8)$ & \\
\hline No & $136(62.4)$ & $54(70.1)$ & $82(58.2)$ & \\
\hline
\end{tabular}

MPV, mean platelet volume.

found to be in correlation with OS. Next, all the factors with a $\mathrm{P}$ value less than 0.10 in univariate analysis were included in multivariate analysis (Table 4). In multivariate analyses, we demonstrated that MPV was an independent prognostic factor in patients with MIBC (hazard ratio (HR): 2.023 [95\% confidence interval (CI): $1.050-3.897, \mathrm{p}=0.025])$.

\section{DISCUSSION}

This study found that MPV is correlated with patient's survival and is an independent risk factor for prognosis. Our findings suggested the potential importance of assessing bladder cancer prognosis by combining clinicopathological characteristics with platelet index.

Thrombocytosis is associated with reduced survival in several cancers, such as lung cancer, ovary cancer, endometrium cancer, rectum cancer, kidney cancer, gastric cancer, pancreas cancer, and breast cancer. Increased platelets facilitate cancer progression and metastasis by promoting angiogenesis and tumor cell establishment at distant sites [17]. For bladder cancer, elevated expression of platelet-derived endothelial cell growth factor is markedly correlated with the tumor progression of bladder cancer [18]. Moreover, platelet-derived growth factor receptor beta is found to be a biomarker for predicting NMIBC recurrence [19]. However, these indices for reflecting activated platelets were expensive and not commonly evaluated in the clinical setting. In accordance with the studies above, the present study indirectly confirmed the findings using a simple marker of platelet activation.

Inflammation may be responsible for the association between MPV and survival. There is a strong linkage between inflammation and cancer [20]. Moreover, platelet plays an essential role in inflammation and cancer. MPV is an early parameter of activated platelets. Large 
Table 2: Baseline characteristics of the patients according to MPV levels

\begin{tabular}{lccc}
\hline Variables & MPV >9.1 & MPV $\leq \mathbf{9 . 1}$ & P value \\
\hline Age $($ years $)$ & $62.2(9.5)$ & $63.8(8.7)$ & 0.189 \\
Gender $($ male, \%) & $62(80.5)$ & $110(78.0)$ & 0.665 \\
Smoker (n, \%) & $15(19.5)$ & $23(16.3)$ & 0.556 \\
Drinking $(\mathrm{n}, \%)$ & $8(10.4)$ & $16(11.3)$ & 0.829 \\
BMI $\left(\mathrm{kg} / \mathrm{m}^{2}\right)$ & $23.4(3.0)$ & $23.5(3.1)$ & 0.781 \\
FPG $(\mathrm{mmol} / \mathrm{L})$ & $5.10(4.80-5.55)$ & $5.00(4.70-5.30)$ & 0.040 \\
WBC $\left(\times 10^{9} / \mathrm{L}\right)$ & $7.25(2.87)$ & $7.06(2.53)$ & 0.615 \\
Neutrophils $\left(\times 10^{9} / \mathrm{L}\right)$ & $4.54(2.49)$ & $4.60(2.35)$ & 0.876 \\
Lymphocytes $\left(\times 10^{9} / \mathrm{L}\right)$ & $2.03(0.71)$ & $1.80(0.56)$ & 0.017 \\
Hemoglobin $(\mathrm{g} / \mathrm{dl})$ & $138.2(17.0)$ & $133.5(18.4)$ & 0.068 \\
Platelet count $\left(\times 10^{9} / \mathrm{L}\right)$ & $199.2(51.1)$ & $223.1(65.7)$ & 0.003 \\
PDW $(\%)$ & $17.2(1.2)$ & $16.7(0.8)$ & $<0.001$ \\
NLR & $2.80(2.67)$ & $2.70(2.17)$ & 0.760 \\
PLR & $119.1(58.3)$ & $128.3(52.6)$ & 0.238 \\
\hline
\end{tabular}

Data are expressed as means (SD) or median (IQR). FPG, fasting plasma glucose; WBC, white blood cell; BMI, body mass index; MPV, mean platelet volume; NLR, neutrophil-to-lymphocyte ratio; PLR, platelet-to-lymphocyte ratio.

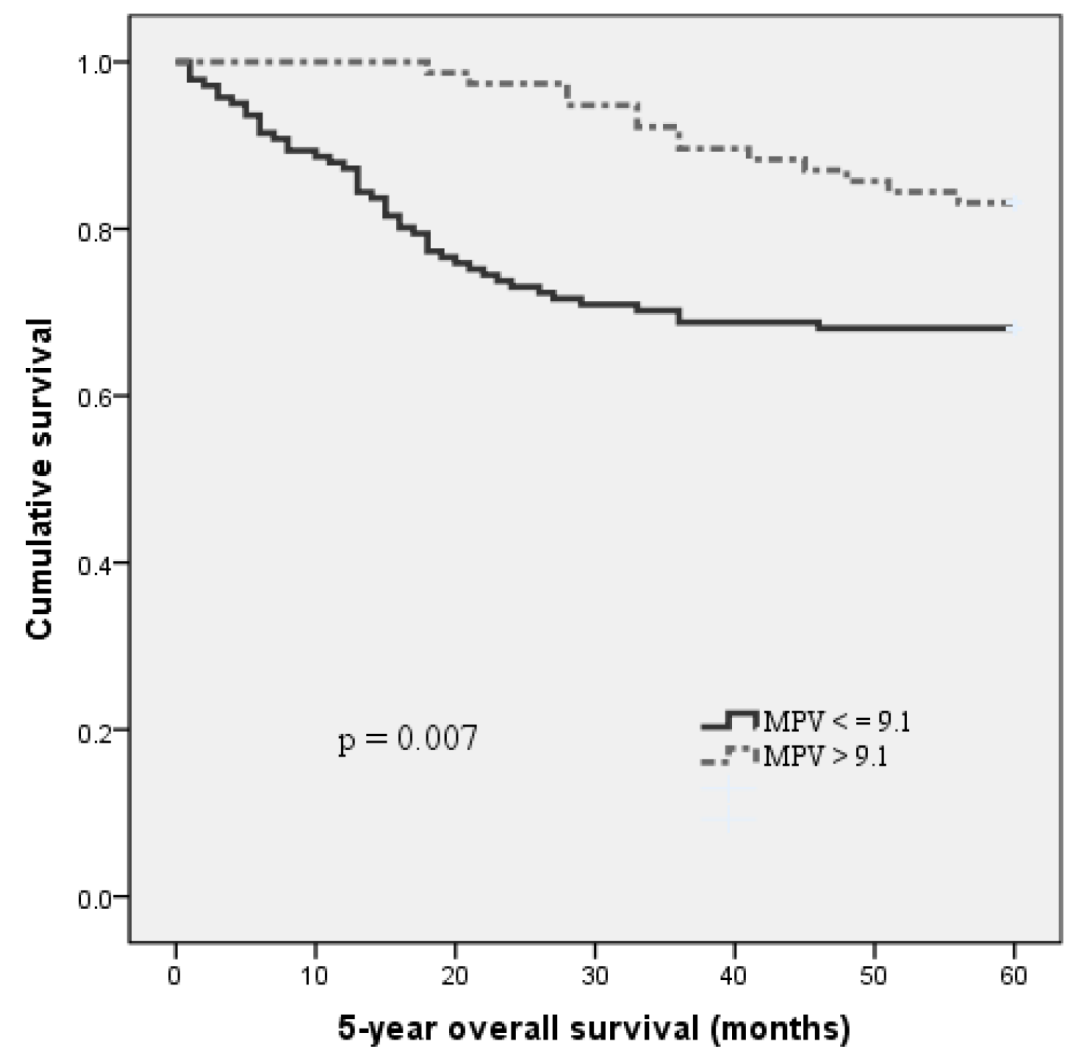

Figure 2: Kaplan-Meier analysis of overall survival in MIBC patients. 
Table 3: Result of the univariate analysis of overall survival in patients with bladder cancer

\begin{tabular}{|c|c|c|c|}
\hline & Hazard ratio & $95 \%$ CI & P-value \\
\hline Age (years) $(\geq 65$ versus $<65)$ & 2.263 & $1.336-3.831$ & 0.002 \\
\hline Gender (male versus female) & 0.569 & $0.270-1.200$ & 0.138 \\
\hline Smoker (yes versus no) & 1.019 & $0.515-2.014$ & 0.957 \\
\hline BMI $\left(\mathrm{kg} / \mathrm{m}^{2}\right)$ & 0.957 & $0.879-1.042$ & 0.311 \\
\hline FPG $(\mathrm{mmol} / \mathrm{L})$ & 0.879 & $0.564-1.370$ & 0.569 \\
\hline $\mathrm{WBC}\left(\times 10^{9} / \mathrm{L}\right)$ & 1.064 & $0.978-1.158$ & 0.148 \\
\hline Hemoglobin (g/dl) & 1.002 & $0.987-1.018$ & 0.778 \\
\hline Platelet count $\left(\times 10^{9} / \mathrm{L}\right)$ & 1.000 & $0.996-1.004$ & 0.945 \\
\hline MPV $(\mathrm{fL})(\leq 9.1$ versus $>9.1)$ & 2.274 & $1.226-4.217$ & 0.009 \\
\hline PDW (\%) & 0.833 & $0.631-1.101$ & 0.199 \\
\hline NLR & 1.082 & $0.997-1.175$ & 0.060 \\
\hline PLR & 1.004 & $1.000-1.008$ & 0.070 \\
\hline \multicolumn{4}{|l|}{ Histology Grade } \\
\hline (G3 versus $\mathrm{G} 1+\mathrm{G} 2)$ & 3.482 & $1.995-6.078$ & $<0.001$ \\
\hline \multicolumn{4}{|l|}{ Lymphovascular invasion } \\
\hline (Yes versus No) & 3.262 & $1.925-5.527$ & $<0.001$ \\
\hline \multicolumn{4}{|l|}{ Multiplicity } \\
\hline (Multifocal versus Solitary) & 0.696 & $0.405-1.196$ & 0.189 \\
\hline \multicolumn{4}{|l|}{ Growth Pattern } \\
\hline (Papillary versus Non-papillary) & 0.374 & $0.198-0.706$ & 0.002 \\
\hline \multicolumn{4}{|l|}{ T stage } \\
\hline$(\mathrm{T} 3+\mathrm{T} 4$ versus $\mathrm{T} 2)$ & 1.648 & $0.982-2.765$ & 0.059 \\
\hline Chemotherapy (yes versus no) & 0.802 & $0.380-1.691$ & 0.562 \\
\hline
\end{tabular}

Abbreviations: see to Tables 1 and 2 .

platelets are more reactive than their smaller counterparts in releasing a variety of pro-inflammatory cytokines, and are more likely to aggregate. The aggregation at sites of inflammation leads to the intensive infiltration of large platelets into vascular and intestinal wall, and the reduction of platelet size [21]. On the other hand, the release rate of small size platelets from the bone marrow increased since excessive pro-inflammatory cytokines interfere with megakaryopoiesis [22]. Therefore, lower MPV values could be suggestive of an enhanced consumption of large platelets in inflammatory states [9]. Recent reports confirmed that low levels of MPV are associated with high-grade inflammatory diseases and reverse in the course of anti-inflammatory therapy [9].

In agreement with our results, Inagaki $\mathrm{N}$ and Kumagai S et al found that low MPV level was associated with poor prognosis in non-small-cell lung cancer [12, 23]. Aksoy et al reported that solid tumors with bone marrow metastasis were more likely to have low MPV levels [24]. These data are also consistent with the current knowledge that anti-platelet is considered to be a part of cancer adjuvant therapy [2].

This is the first time to investigate the correlation between MPV and clinicopathologic parameters, as well as prognosis in patients with MIBC. In addition, we established platelet activation in MIBC using an inexpensive laboratory indicator. Further experiments are needed to elucidate the underlying mechanism. Activated platelets may be considered as an excellent therapeutic target for MIBC patients. However, there are several limitations in our study. First, this study was retrospective and further prospective studies are needed to confirm and update our conclusion. Second, we were unable to explore the exact mechanism of decreased MPV in bladder cancer. Third, the cases were composed of Chinese. The application to other ethnic groups still needs further investigation. 
Table 4: Result of the multivariate analysis of overall survival in patients with bladder cancer

\begin{tabular}{|c|c|c|c|}
\hline & Hazard ratio & $95 \% \mathrm{CI}$ & P-value \\
\hline Age $($ years $)(\geq 65$ versus $<65)$ & 1.785 & $1.037-3.074$ & 0.031 \\
\hline MPV $(\mathrm{fL})(\leq 9.1$ versus $>9.1)$ & 2.023 & $1.050-3.897$ & 0.025 \\
\hline NLR & 1.000 & 0.994-1.007 & 0.892 \\
\hline PLR & 1.062 & $0.923-1.223$ & 0.402 \\
\hline \multicolumn{4}{|l|}{ Histology Grade } \\
\hline (G3 versus $\mathrm{G} 1+\mathrm{G} 2)$ & 3.404 & $1.902-6.090$ & $<0.001$ \\
\hline \multicolumn{4}{|l|}{ Lymphovascular invasion } \\
\hline (Yes versus No) & 3.272 & $1.805-5.933$ & $<0.001$ \\
\hline \multicolumn{4}{|l|}{ Growth Pattern } \\
\hline (Papillary versus Non-papillary) & 0.419 & $0.208-0.841$ & 0.014 \\
\hline \multicolumn{4}{|l|}{ T stage } \\
\hline (T3+T4 versus $\mathrm{T} 2)$ & 0.546 & $0.288-1.037$ & 0.064 \\
\hline
\end{tabular}

CI, confidence interval. Abbreviations: see to Tables 1 and 2 .

In conclusion, reduced MPV has prognostic value in MIBC patients. Future studies need to be focused on the underlying mechanisms of MPV in MIBC.

\section{MATERIALS AND METHODS}

\section{Study population}

This study consisted of 218 consecutive MIBC cases (mean age $63.2 \pm 9.0$ years, range $31-82$ years). Cases were admitted to Harbin Medical University Cancer Hospital, Harbin Medical University between January 2009 and December 2009. All patients undergone radical cystectomy. The pathologic diagnoses of MIBC were evaluated by pathologists from biopsy reports. None of the patients received preoperative chemotherapy or radiation therapy. Patients were excluded if they had hematological disorders, coronary artery disease, hypertension, diabetes mellitus, and medical treatment with anticoagulant, statins, and acetylic salicylic acid. Standard demographic and clinicopathological data were collected from the patients' records in hospital. Survival data were obtained through follow-up. Overall survival (OS) was defined as the interval from the date of diagnosis to death or last follow-up. The median follow-up time was 60 months.

Venous blood samples after an 10-hour overnight fasting were collected from the individuals within 1 week prior to surgery. White blood cell (WBC), haemoglobin, and platelet indices were measured by an autoanalyzer (Sysmex XE-2100, Kobe, Japan). The whole blood samples were collected in EDTA-containing tubes, and all samples were processed within 30 minutes after blood collection. The platelet-to-lymphocyte ratio (PLR) was calculated as the absolute platelet count measured in $\times 10^{9} / \mathrm{L}$ divided by the absolute lymphocyte count measured in $\times 10^{9} / \mathrm{L}$. The neutrophil-to-lymphocyte ratio (NLR) was calculated as the absolute neutrophil count measured in $\times 10^{9} / \mathrm{L}$ divided by the absolute lymphocyte count measured in $\times 10^{9} / \mathrm{L}$.

The Institutional Ethics Review Board of Harbin Medical University Cancer Hospital of Harbin Medical University approved this study prior to commencement of data collection and waived the informed consent requirement because it was a retrospective study.

\section{Statistical analysis}

All continuous data are expressed as means $\pm \mathrm{SD}$ or medians (interquartile range), and the categorical data are expressed in percentages. The continuous variables were compared with Student's t test or the Mann-Whitney U test, as appropriate, whereas categorical variables were compared with the Chisquare test. The Kaplan-Meier method was used for descriptive analysis of survival curves; survival curves were compared using log-rank tests. We used the univariate Cox proportional hazards model for identifying the contribution of each variables. The multivariate Cox proportional hazards models were used to determine adjusted hazard ratios for survival. Variables with P-values $<0.1$ were selected for the multivariate analysis. Receiver-operating characteristics (ROC) curve analysis was performed to identify cut-off value of MPV. $\mathrm{P}<0.05$ was considered to indicate statistically significant differences in all tests. All statistical analyses were performed using 
SPSS Statistics version 22.0 (SPSS Inc., Chicago, IL, USA).

\section{CONFLICTS OF INTEREST}

The authors declare no conflict of interest.

\section{GRANT SUPPORT}

This work was supported financially by grants from the Harbin Medical University Cancer Hospital (JJZD2017-05) and postdoctoral research project of Heilongjiang Province (No. LBH-Z16190).

\section{REFERENCES}

1. DeSantis CE, Lin CC, Mariotto AB, Siegel RL, Stein KD, Kramer JL, Alteri R, Robbins AS, Jemal A. Cancer treatment and survivorship statistics, 2014. CA Cancer J Clin. 2014;64:252-271.

2. Mezouar S, Frere C, Darbousset R, Mege D, Crescence L, Dignat-George F, Panicot-Dubois L, Dubois C. Role of platelets in cancer and cancer-associated thrombosis: experimental and clinical evidences. Thromb Res. 2016;139:65-76.

3. Suzuki K, Aiura K, Kitagou M, Hoshimoto S, Takahashi S, Ueda M, Kitajima M. Platelets counts closely correlate with the disease-free survival interval of pancreatic cancer patients. Hepatogastroenterology. 2004;51:847-853.

4. Long Y, Wang T, Gao Q, Zhou C. Prognostic significance of pretreatment elevated platelet count in patients with colorectal cancer: a meta-analysis. Oncotarget. 2016;7:81849-81861. doi: 10.18632/oncotarget.13248.

5. Pietrzyk L, Plewa Z, Denisow-Pietrzyk M, Zebrowski $\mathrm{R}$, Torres K. Diagnostic power of blood parameters as screening markers in gastric cancer patients. Asian Pac J Cancer Prev. 2016;17:4433-4437.

6. Ekici H, Malatyalioglu E, Kokcu A, Kurtoglu E, Tosun M, Celik H. Do leukocyte and platelet counts have benefit for preoperative evaluation of endometrial cancer. Asian Pac J Cancer Prev. 2015;16:5305-5310.

7. Qiu J, Yu Y, Fu Y, Ye F, Xie X, Lu W. Preoperative plasma fibrinogen, platelet count and prognosis in epithelial ovarian cancer. J Obstet Gynaecol Res. 2012;38:651-657.

8. Seretis C, Youssef H, Chapman M. Hypercoagulation in colorectal cancer: what can platelet indices tell us. Platelets. 2015;26:114-118.

9. Gasparyan AY, Ayvazyan L, Mikhailidis DP, Kitas GD. Mean platelet volume: a link between thrombosis and inflammation. Curr Pharm Des. 2011;17:47-58.

10. Shen XM, Xia YY, Lian L, Zhou C, Li XL, Han SG, Zheng Y, Gong FR, Tao M, Mao ZQ, Li W. Mean platelet volume provides beneficial diagnostic and prognostic information for patients with resectable gastric cancer. Oncol Lett. 2016;12:2501-2506.
11. Tanriverdi O, Menekse S, Teker F, Oktay E, Nur PK, Gunaldi M, Kocar M, Kacan T, Bahceci A, Avci N, Akman T, Cokmert S, Yesil-Cinkir H, Teoman YM. The mean platelet volume may predict the development of isolated bone metastases in patients with breast cancer: a retrospective study of the Young Researchers Committee of the Turkish Oncology Group (TOG). J BUON. 2016;21:840-850.

12. Kumagai S, Tokuno J, Ueda Y, Marumo S, Shoji T, Nishimura T, Fukui M, Huang CL. Prognostic significance of preoperative mean platelet volume in resected non-smallcell lung cancer. Mol Clin Oncol. 2015;3:197-201.

13. Kemal Y, Demirağ G, Ekiz K, Yücel I. Mean platelet volume could be a useful biomarker for monitoring epithelial ovarian cancer. J Obstet Gynaecol. 2014;34:515-518.

14. Yun ZY, Li N, Zhang X, Zhang H, Bu Y, Sun Y, Liu T, Wang RT, Yu KJ. Mean platelet volume, platelet distribution width and carcinoembryonic antigen to discriminate gastric cancer from gastric ulcer. Oncotarget. 2017 Mar 4. https:// doi.org/10.18632/oncotarget.15898. [Epub ahead of print]

15. Gao L, Zhang H, Zhang B, Zhang L, Wang C. Prognostic value of combination of preoperative platelet count and mean platelet volume in patients with resectable non-small cell lung cancer. Oncotarget. 2017;8:15632-15641. doi: 10.18632/oncotarget.14921.

16. Zhuang Q, Xiang L, Xu H, Fang F, Xing C, Liang B, Yu $\mathrm{K}$, Feng J. The independent association of mean platelet volume with overall survival in multiple myeloma. Oncotarget. 2016;7:62640-62646. doi: 10.18632/ oncotarget.11551.

17. Meikle CK, Kelly CA, Garg P, Wuescher LM, Ali RA, Worth RG. Cancer and thrombosis: the platelet perspective. Front Cell Dev Biol. 2016;4:147.

18. Li N, Kanda K, Fukumori $\mathrm{T}$, Inoue $\mathrm{Y}$, Nishitani $\mathrm{M}$, Kanayama H, Kagawa S. Expression of vascular endothelial growth factor isoforms and platelet-derived endothelial cell growth factor in bladder cancer. Urol Oncol. 2000;6:10-15.

19. Feng J, He W, Song Y, Wang Y, Simpson RJ, Zhang X, Luo G, Wu J, Huang C. Platelet-derived growth factor receptor beta: a novel urinary biomarker for recurrence of non-muscle-invasive bladder cancer. PLoS One. 2014;9:e96671.

20. Mantovani A, Allavena P, Sica A, Balkwill F. Cancer-related inflammation. Nature. 2008;454:436-444.

21. Gasparyan AY, Sandoo A, Stavropoulos-Kalinoglou A, Kitas GD. Mean platelet volume in patients with rheumatoid arthritis: the effect of anti-TNF- $\alpha$ therapy. Rheumatol Int. 2010;30:1125-1129.

22. Cornillie F, Hanauer SB, Diamond RH, Wang J, Tang $\mathrm{KL}, \mathrm{Xu} \mathrm{Z}$, Rutgeerts P, Vermeire S. Postinduction serum infliximab trough level and decrease of C-reactive protein level are associated with durable sustained response to 
infliximab: a retrospective analysis of the ACCENT I trial. Gut. 2014;63:1721-1727.

23. Inagaki N, Kibata K, Tamaki T, Shimizu T, Nomura S. Prognostic impact of the mean platelet volume/platelet count ratio in terms of survival in advanced non-small cell lung cancer. Lung Cancer. 2014;83:97-101.
24. Aksoy S, Kilickap S, Hayran M, Harputluoglu H, Koca E, Dede DS, Erman M, Turker A. Platelet size has diagnostic predictive value for bone marrow metastasis in patients with solid tumors. Int J Lab Hematol. 2008;30:214-219. 